\title{
Prospective study of treatment of extraarticular fractures of distal end radius by cross $K$ wire fixation and cast immobilisation and its comparison with Kapandji's method of intrafocal pinning anatomically and functionally
}

\author{
Paresh Patil, Kiran Gaonkar, Adish Patil, Nishant Gaonkar, \\ Ketan Gupta*, Nirav Patel, Himanshu Kulkarni
}

Department of Orthopedics, Krishna institute of Medical Sciences, Karad, Maharashtra, India

Received: 03 February 2015

Accepted: 03 March 2015

*Correspondence:

Dr. Ketan Gupta,

E-mail: ketangupta15@gmail.com

Copyright: () the author(s), publisher and licensee Medip Academy. This is an open-access article distributed under the terms of the Creative Commons Attribution Non-Commercial License, which permits unrestricted non-commercial use, distribution, and reproduction in any medium, provided the original work is properly cited.

\begin{abstract}
Background: Distal radius fractures account for $17 \%$ of all fractures in adults. The fracture of the lower end of radius crushes the mechanical foundation of man's most elegant tool, the hand. No other fracture has a greater potential to devastate hand function. Extra-articular fractures (type A in the AO classification) require avoidance of malunion with angulation and shortening. Malalignment results in limitation of movement, changes in load distribution, midcarpal instability and an increased risk of osteoarthritis of the radiocarpal joint. Aims and objectives: Treatment of extraarticular fractures of distal end radius by cross $\mathrm{K}$ wire fixation and cast immobilisation and its comparison with Kapandji's method of intrafocal pinning anatomically and functionally.

Methods: Total 50 cases were included in the study. First 25 cases were treated by Kapandji's method and next 25 cases were treated by cross $\mathrm{K}$ wire fixation and all cases were given below elbow cast after internal fixation. Patients were followed up at regular intervals and Anatomical and functional outcomes were evaluated in all the patients.

Results: In our study anatomical end results were satisfactory in $96 \%$ and unsatisfactory in $4 \%$ of the subjects treated with cross $\mathrm{K}$ wire fixation and $72 \%$ and $28 \%$ in cases treated by Kapandji's method whereas Functional end results were excellent in $28 \%$ cases, good in $68 \%$ cases, fair in $4 \%$ case and poor in $0 \%$ cases treated with cross $\mathrm{k}$ wire fixation and $12 \%, 60 \%, 24 \%$ and $4 \%$ in cases treated by Kapandji's method.

Conclusion: Cross $\mathrm{K}$ wire method proved to be better than Kapandji's method of intrafocal $\mathrm{K}$ wire fixation both functionally and anatomically.
\end{abstract}

Keywords: Extraarticular fractures, Distal end radius, Cross K wire, Kapandji’s method

\section{INTRODUCTION}

Distal radius fractures account for $17 \%$ of all fractures in adults. Thousands of articles were published after Abraham Colles described a very common fracture of the distal end radius in 1814 in the Edinburgh Medical and Surgical Journal, have not yet created a consensus as a treatment programme. ${ }^{1}$ The fracture of the lower end of radius crush the mechanical foundation of man's most elegant tool, the hand. No other fracture has a greater potential to devastate hand function. ${ }^{2}$ A thorough understanding of the pathophysiology and treatment of distal end radius is important as high energy trauma to distal end radius in adults is becoming more common and 
long term functional results are unclear, these common injuries must be evaluated thoroughly and treated adequately. The causes of injury are fall on outstretched hand, work related accidents, car accidents, sport injuries. ${ }^{2}$ The typical mechanism of a dorsally displaced distal radius fracture is a fall on outstretched hand. This type of injury results in tensile forces across the volar surface (compression side), compressive forces on the dorsal surface (tension side), and supination of the distal fracture fragment. Compression and torsion across the articular surface can cause various patterns of intraarticular displacement. Stable reduction of the distal radius fractures requires this biomechanical relationship to be re-established. ${ }^{3}$ Studies have shown that distal radius fractures are associated with tears of the triangular fibrocartilage complex (TFCC), scapholunate ligament, lunotriquetral ligament. Generally the carpal ligament injuries including TFCC that are associated with distal radius fractures that do not show visible deformities on plain radiographs are not treated. Accurate fracture reduction results into healing of the ligaments during the post-operative or postreduction immobilisation period. ${ }^{4}$ Distal end radius fractures include Barton's fracturedorsal, Barton's fracture-volar, Chauffer's fracture, Colle's fracture, intra-articular fracture distal radius. The treatment options ${ }^{5}$ are quiet varied depending on the exact nature of fracture, activity level and surgeons personal preferences. There are no contraindications to the nonsurgical management of a closed distal radius fracture. Indications for surgical treatment should be based on radiographic findings after initial reduction, expected functional needs, associated medical conditions and other traumatic injuries. The involvement of all these listed factors will together bring a good final outcome to the proposed study. ${ }^{5}$ This study is intended towards the study of extra articular type of fractures of distal end radius in adults, their management with modalities of treatment involving closed reduction and cross $\mathrm{K}$ wire pinning and below elbow cast and its comparison with intrafocal pinning method of Kapandji's and the relative complications. AO classification for distal end radius fractures was considered and the cases were treated accordingly. Lindstrom's; ${ }^{6}$ Gartland and Werley ${ }^{7}$ criteria was used for anatomical and functional end results.

\section{Lindstrom's criteria ${ }^{6}$ for anatomical end results}

Grade 1

- No significant deformity

- Dorsal angulation not exceeding neutral position

- $\quad$ Radial shortening $<3 \mathrm{~mm}$

Grade 2

- $\quad$ Slight deformity

- Dorsal angulation 1 to 10 degrees
- $\quad$ Radial shortening 3 to $6 \mathrm{~mm}$

Grade 3

- $\quad$ Moderate deformity

- Dorsal angulation 11 to 14 degrees

- $\quad$ Radial shortening 7 to $11 \mathrm{~mm}$

Grade 4

- $\quad$ Severe deformity

- $\quad$ Dorsal angulation >15 degrees

- $\quad$ Radial shortening $>12 \mathrm{~mm}$

Lindstrom's criteria ${ }^{6}$ for functional end results

Excellent

- No deformity

- $\quad$ No residual disability

- $\quad$ Full wrist and forearm movements

- No loss of grip strength

Good

- $\quad$ Minimal deformity

- $\quad$ Residual deformity

- $\quad$ Loss of movementsupto 20 degrees

- $\quad$ Slight loss of grip strength

Fair

- $\quad$ Moderate deformity

- $\quad$ Moderate disability

- Loss of movementsupto 40 degrees, Moderate loss of grip strength

Poor

- $\quad$ Gross deformity

- Gross disability

- Gross limitation of wrist and forearm movements

- $\quad$ Severe loss of grip strength 
Table 1: Gartland and werley ${ }^{7}$ criteria for anatomical results after Sarmiento (Modified by Lidstrom).

\begin{tabular}{|c|c|}
\hline Results & Criteria \\
\hline Excellent & $\begin{array}{l}\text { No significant deformity } \\
\text { Dorsal angulation < degrees } \\
\text { Shortening }<3 \mathrm{~mm} \\
\text { Loss of radial deviation }<4 \text { degrees }\end{array}$ \\
\hline Good & $\begin{array}{l}\text { Slight deformity } \\
\text { Dorsal angulation 1-10 degrees } \\
\text { Shortening 3-6 mm } \\
\text { Loss of radial deviation 5-9 degrees }\end{array}$ \\
\hline Fair & $\begin{array}{l}\text { Moderate deformity } \\
\text { Dorsal angulation } 11-14 \text { degrees } \\
\text { Shortening } 7-11 \mathrm{~mm} \\
\text { Loss of radial deviation } 10-14 \text { degrees }\end{array}$ \\
\hline Poor & $\begin{array}{l}\text { Dorsal angulation }>15 \text { degrees } \\
\text { Shortening more than or equal to } 12 \mathrm{~mm} \\
\text { Loss of radial deviation }>15 \text { degrees }\end{array}$ \\
\hline
\end{tabular}

Table 2: Modified Gartland \& Werley's wrist grading system.

\begin{tabular}{|llll|}
\hline Subjective & Points & Objective & Points \\
\hline Pain & 20 & Motion & 20 \\
\hline Function & 20 & Strength (grip, pinch) & 10 \\
\hline Motion & 10 & Healing & 10 \\
\hline & & $\begin{array}{l}\text { Postoperative ulnar } \\
\text { variance }\end{array}$ & 10 \\
\cline { 3 - 4 } & & Complication & 10 \\
\hline Total & 50 & Total & 50 \\
\hline
\end{tabular}

Table 3: Grading of the result.

\begin{tabular}{|ll|}
\hline Grading of the result \\
\hline Excellent & $91-100$ points \\
\hline Good & $81-90$ points \\
\hline Fair & $66-80$ points \\
\hline Poor & $0-65$ points \\
\hline
\end{tabular}

\section{Aims and objectives}

1. To study extra articular two part and dorsal tilt type of fractures with dorsal communition of distal end radius in adults.

2. The management of distal end radius fractures in adults with closed reduction and internal fixation with percutaneous cross pinning by using K-wires and below elbow cast application.

3. Comparing the outcome of these patients with outcome of patients treated with Kapandji's method of intrafocal pinning and below elbow cast application.

4. To develop a method of cross pinning with K-wires in desired directions and below elbow cast as a modality of treatment for two part fractures of distal end radius with dorsal tilt.

\section{METHODS}

The cases between age group 18 to 60 years with fractures of distal end radius AO OTA type A2.1, A2.2, A3.1, A3.2 and A3.3 were included in the study. These cases were treated with cross pinning by two Kwires and below elbow cast or Kapandji's method of intrafocal pinning with below elbow cast. First 25 cases were treated by Kapandji's method and next 25 cases were treated by cross $\mathrm{K}$ wire fixation and all cases were given below elbow cast after internal fixation. All procedures were done in the operation theater under short general or i.v. regional anesthesia with monitoring of patient's pulse, blood pressure, $\mathrm{SPO}_{2}$ and ECG recording after aseptic preparation of the effected extremity. The patient was placed on a radiolucent table in supine position. Complete visualization of the fracture pattern of the involved bone was done with the help of C-Arm fluoroscopy in antero-posterior and lateral views. Kapandjji described a technique of trapping the major fragment by buttressing to prevent displacement. Small incision was made over dorsal and radial side of radial fracture site to be sure that the pins will not be driven across the extensor tendons. $\mathrm{K}$ wires inserted into the fracture sites which are then used to pry the distal fragment into optimal position. The pins are then levered until the proper anatomy is restored, and subsequently the pins are then driven proximally and oblique into the cortex of proximal fragment.

The fragments are thus buttressed from displacing dorsally or proximally. In addition to being relatively simple and inexpensive, this technique can be very effective. In method involving cross $\mathrm{K}$ wire fixation fracture was reduced by traction and manipulation and two K wires were used first from tip of styloid process to medial cortex of proximal fragment and second from lateral cortex towards sigmoid notch crossing the first wire.

Maintenance of reduction after drilling of K-Wires was confirmed with fluoroscopic imaging. The K-Wires drilled were bent approximately $1 \mathrm{~cm}$ from the point of insertion and cut using a plier. A sterile dressing using povidone iodine was kept at pin site. Well-padded below elbow cast was given keeping the wrist in neutral position extending from metacarpophalangeal joints of fingers to the proximal part of forearm, just distal to elbow. Postoperatively hand was elevated for 12 hours with monitoring of neurovascular status. Early motion of digits, shoulder was encouraged. Patient was discharged and followed up at the end of three weeks, six weeks, three months, six months. At the end of four weeks check X-ray were taken of both affected and unaffected wrists to look for loss of reduction, pin loosening. $\mathrm{K}$ wires were removed by creating a window in the cast and closing the window after $\mathrm{K}$ wire removal. At the end of six weeks 
cast was removed. Patient was started with physiotherapy consisting of wrist movements, supination, pronation and finger grip exercises. Patients were discharged after 24 hours of the procedure. The patients of both groups were asked to follow up 1 month, 3 months and 6 months from the day of surgery and radiographs were taken.

\section{The following criteria ${ }^{8,9}$ were used for assessment during follow up}

1 Month

a) Pain

b) Pin loosening.

c) Range of movement of the joints proximal and distal to the fractured bone fixed with K-wires (only in early mobilization group).

d) Loss of reduction.

e) Incidence of complex regional pain syndrome.

3 Months

a) Pain.

b) Range of movement of the joints proximal and distal to the fractured bone fixed with K-wires for both the groups.

c) Soft tissue problems.

d) Fracture union.

e) Incidence of complex regional pain syndrome.

6 Months

a) Pain.

b) Range of movement of the joints proximal and distal to the fractured bone fixed with K-wires for both the groups.

c) Fracture union.

d) Incidence of complex regional pain syndrome.

In this study wrist was immobilized in neutral position with below elbow cast extending from the metacarpophalangeal joints of fingers to the proximal part of forearm just distal to elbow. In this position of wrist incidence of neuropathies, carpal tunnel syndrome and ischaemic complications were not there. Patients were started with physiotherapy for finger ROM, elbow and shoulder ROM exercises from $2^{\text {nd }}$ post-operative day.

\section{RESULTS}

The quality of recovery was determined by range of motion, grip strength, peri and post-operative complications, patient satisfaction and radiographic evaluation by the method of Gartland and Werleys wrist grading system ${ }^{7}$ in which equal emphasis is placed for a maximum possible findings- each with 50 points for a maximum possible score of 100 points. AP and lateral Xrays of the wrist were used for various measurements. The radiographs made at the time of the latest follow-up were evaluated for joint congruity comparing with unaffected extremity. The result for each fracture was graded as excellent, good, fair and poor with use of both these systems. Functional end results were assessed by the Lindstroms criteria. ${ }^{8}$ Anatomical and radiological results were determined by the Lidstrom classification. This include an average flexion-extension arc of $>120$ degrees and an average supination-pronation of $>150$ degrees. The average grip strength exceeded $80 \%$ in comparison with that of the contralateral, unaffected hand with arrange of 60 to $100 \%$. Most of these patients were considered to have satisfactory radiographic results of grade 1 and 2 using the modified Lidstrom classification.

Few complications were noted:

1. Pin tract inflammation without signs of infection in 7 patients with $\mathrm{K}$ wires.

2. $\mathrm{K}$ wire loosening was noted in 6 cases.

3. 2 patients experienced symptoms of median nerve compression pre-operatively which resolved spontaneously after accurate fracture reduction thus negating the need for surgical nerve decompression.

4. Wrist arthritis developed in 1 case.

5. Patient satisfaction was consistently high.

Majority of the patients returned to their former activities of daily living with no significant limitations and no secondary operations have been required till date, except a planned procedure with one with which we have lost the follow-up. Thus, both of these modalities of treatment for distal end radius fractures used with thorough knowledge of the fracture type, proper fixation of the fracture with good anatomical reduction and adequate physiotherapy gives a functional wrist in the fractures of the distal end of radius. Even though some motion is lost, $75 \%$ recovery of mobility and grip strength can be anticipated.

Table 4: Gender distribution.

\begin{tabular}{|lll|}
\hline Gender & $\begin{array}{l}\text { Number } \\
\text { of cases }\end{array}$ & $\begin{array}{l}\text { Percentage } \\
(\%)\end{array}$ \\
\hline Male & 35 & $70 \%$ \\
\hline Female & 15 & $30 \%$ \\
\hline
\end{tabular}




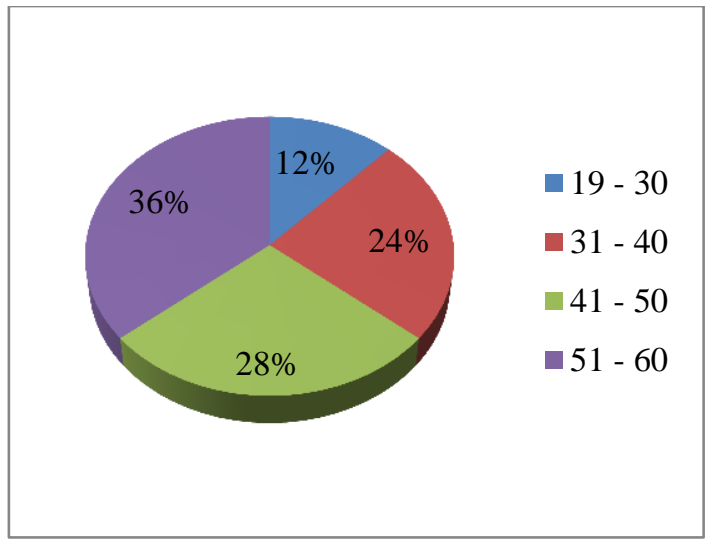

Figure 1: Shows age distribution of the cases in our study.

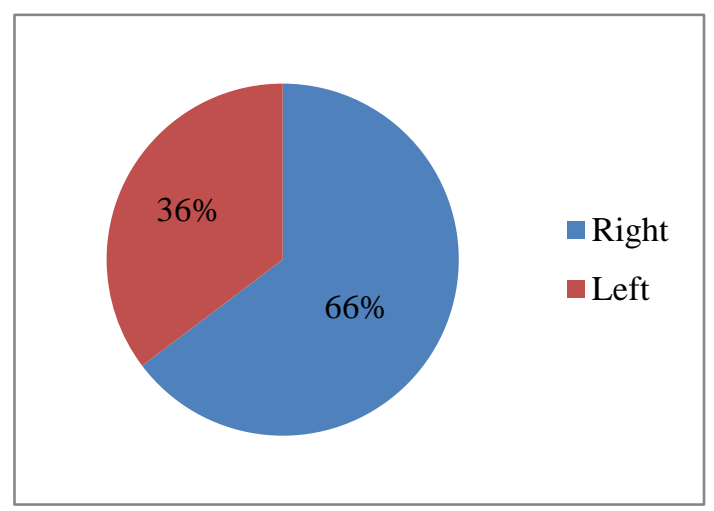

Figure 2: Shows the involved extremity of the cases in our study.

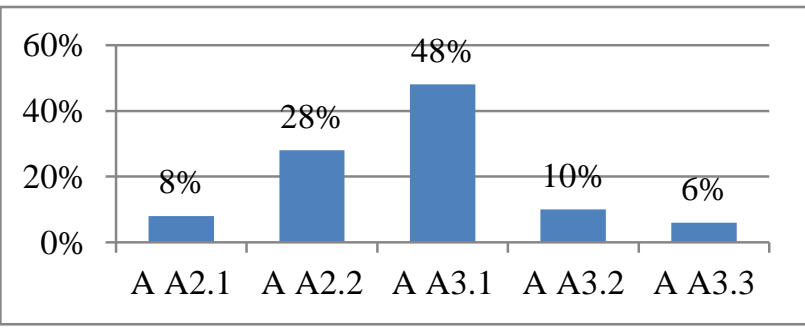

Figure 3: Shows type of fracture in the cases in our study.

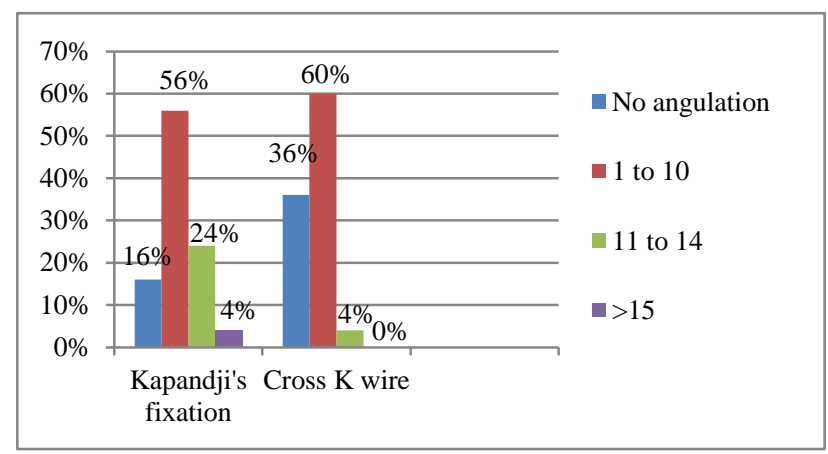

Figure 4a: Shows radiological evaluation of dorsal tilt correction in degree.

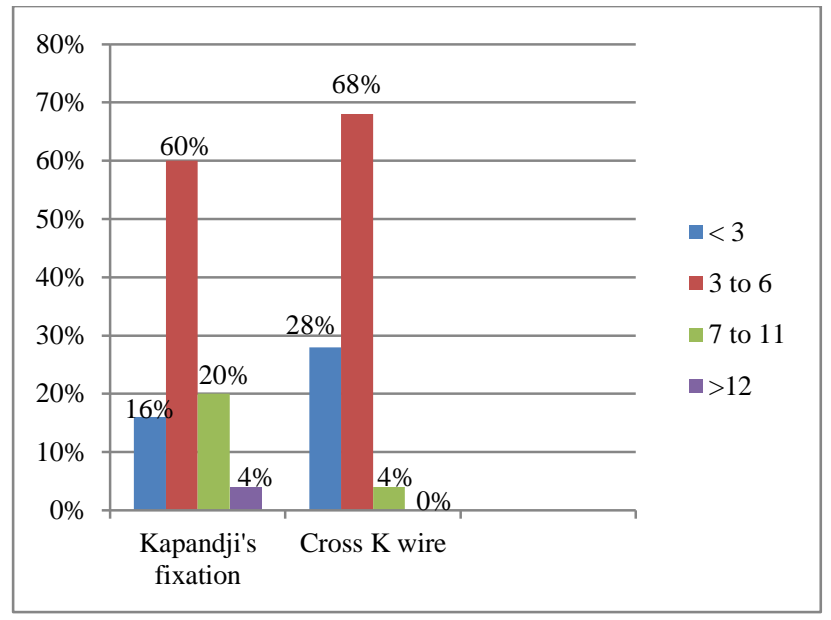

Figure 4b: Shows radiological evaluation of radial shortening in $\mathbf{m m}$.

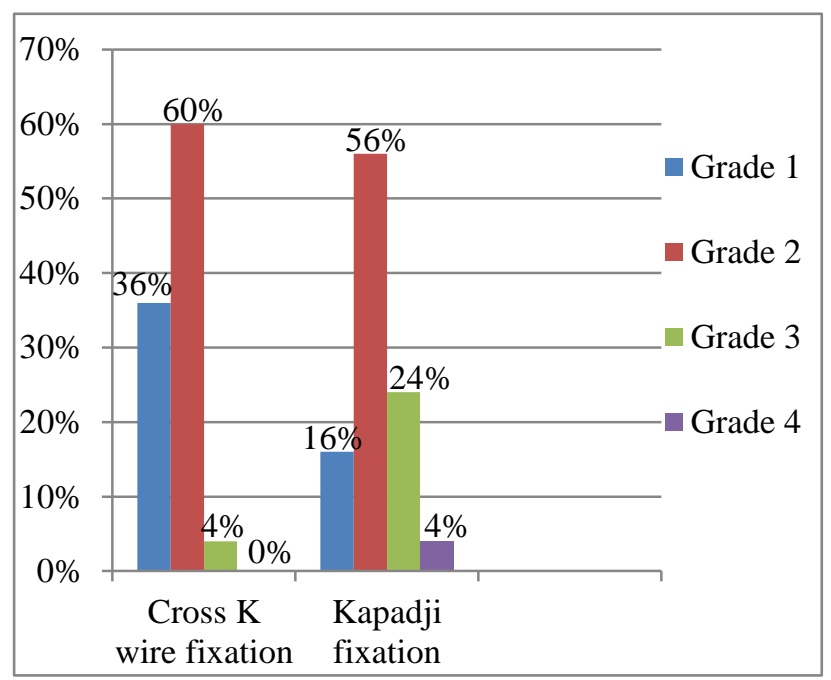

Figure 5: Shows anatomical end results of all the cases.

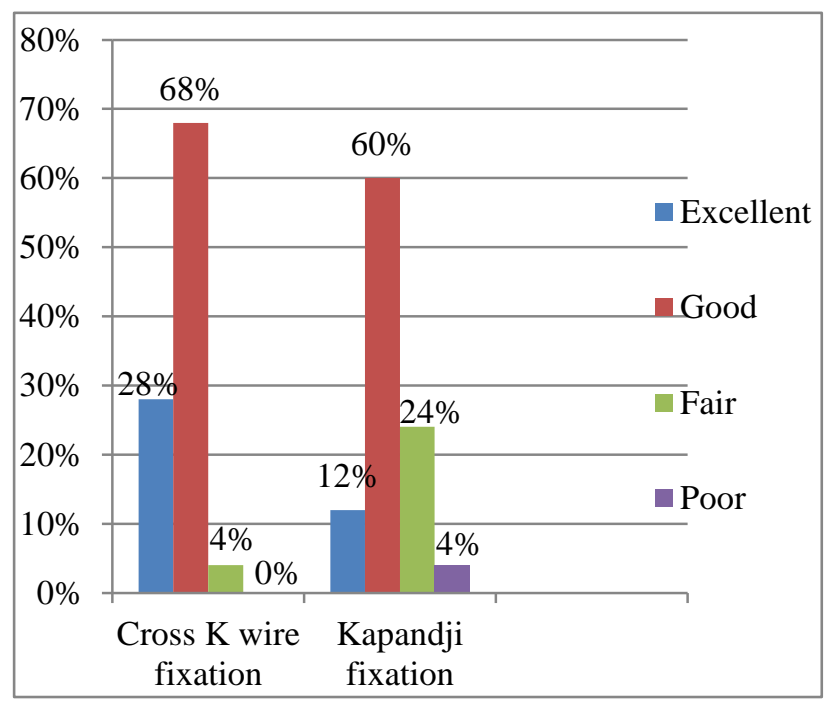

Figure 6: Shows functional end results of all the cases. 
Table 5a: Summary of results of cases treated by Kapandji's method with classification.

\begin{tabular}{|c|c|c|c|}
\hline $\begin{array}{l}\text { Type of } \\
\text { fracture }\end{array}$ & $\begin{array}{l}\text { No. of cases } \\
\text { of Kapandji's } \\
\text { method }\end{array}$ & $\begin{array}{l}\text { Anatomical } \\
\text { end result }\end{array}$ & $\begin{array}{l}\text { Functional } \\
\text { end result }\end{array}$ \\
\hline A A2 1 & 3 & $\begin{array}{l}\text { Grade } 2 \rightarrow 2 \\
\text { Grade } 3 \rightarrow 1\end{array}$ & $\begin{array}{l}\text { Good } \rightarrow 2 \\
\text { Fair } \rightarrow 1\end{array}$ \\
\hline A A 22 & 5 & $\begin{array}{l}\text { Grade } 1 \rightarrow 1 \\
\text { Grade } 2 \rightarrow 3 \\
\text { Grade } 3 \rightarrow 1\end{array}$ & $\begin{array}{l}\text { Excellent } \rightarrow 1 \\
\text { Good } \rightarrow 4\end{array}$ \\
\hline A A3 1 & 13 & $\begin{array}{l}\text { Grade } 1 \rightarrow 3 \\
\text { Grade } 2 \rightarrow 8 \\
\text { Grade } 3 \rightarrow 2\end{array}$ & $\begin{array}{l}\text { Excellent } \rightarrow 2 \\
\text { Good } \rightarrow 8 \\
\text { Fair } \rightarrow 3\end{array}$ \\
\hline A A 32 & 3 & $\begin{array}{l}\text { Grade } 2 \rightarrow 1 \\
\text { Grade } 3 \rightarrow 2\end{array}$ & $\begin{array}{l}\text { Good } \rightarrow 1 \\
\text { Fair } \rightarrow 2\end{array}$ \\
\hline A A 33 & 1 & Grade $4 \rightarrow 1$ & Poor $\rightarrow 1$ \\
\hline
\end{tabular}

Table 5b: Summary of results of cases treated by cross $\mathrm{K}$ wire method with classification.

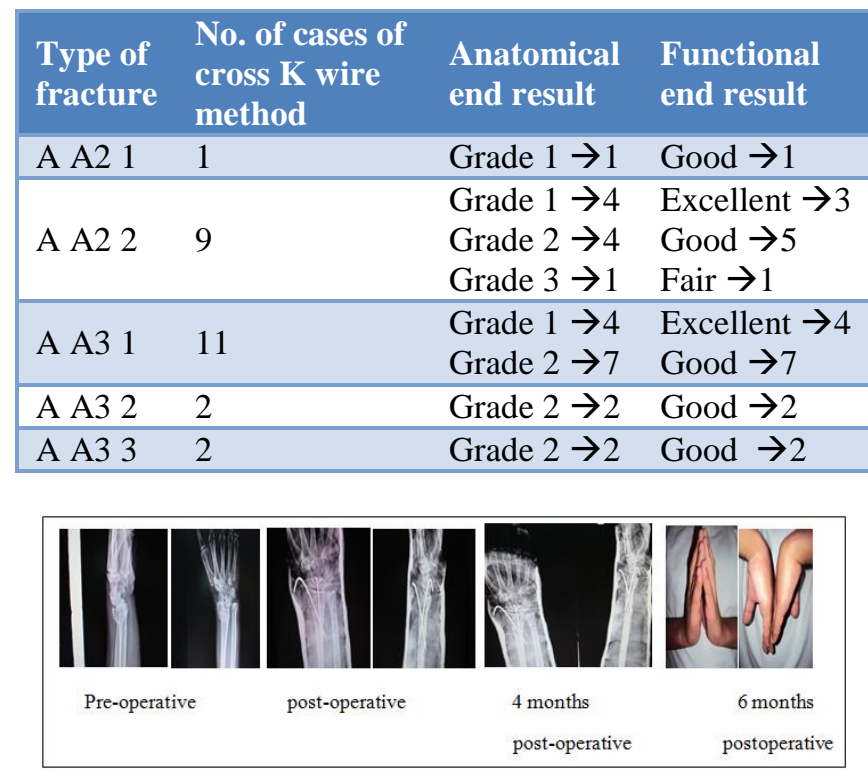

Figure 7: Shows a case treated by Kapandji’s fixation.

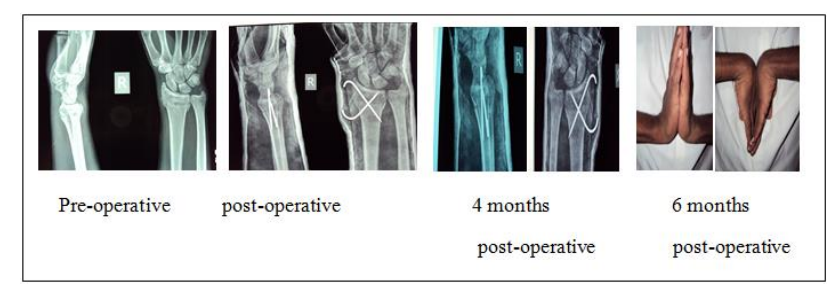

Figure 8: Shows a case treated by cross $k$ wire fixation.

\section{DISCUSSION}

The injuries to the lower end of radius are not only encountered in the emergency department setting, but the mobility and delicate functional requirements of the hand make accurate diagnosis and treatment crucial to avoiding long-term loss of function and disability. ${ }^{10}$ The importance of anatomic reduction has been demonstrated by clinical studies as well as by laboratory assessment of force and stress studies. In fractures with articular displacement greater than $2 \mathrm{~mm}$, radial shortening greater than $5 \mathrm{~mm}$ or dorsal angulation greater than $20^{\circ}$, suboptimal results have been reported in previously published studies. Accurate reduction of the fracture is the first step in the treatment of distal radial fractures. Many options are available to maintain this initial reduction. The most common traditional method is closed reduction and cast immobilization, but this often fails to prevent early radial collapse and is associated with a high risk of malunion, joint stiffness and painful wrist. Hence, this method is for low-demand elderly patients ${ }^{11}$. External fixators can maintain radial length and radial inclination by ligamentotaxis, but cannot effectively maintain palmar tilt. Also complication rates as high as $60 \%$ have been reported with the use of external fixators. These mainly include pin loosening, pin tract infection, reflex sympathetic dystrophy, radial sensory neuritis and delayed union. Thus, external fixators are better avoided in non-comminuted extra-articular distal radial fractures. Percutaneous pinning is simple, minimally invasive, and prevents redisplacement of fracture fragments adequately. Therefore this method is supposed to be an appropriate treatment for elderly patients with severely displaced and unstable fractures of distal end of radius. ${ }^{11}$ In this study we have brought together an observational report of 50 cases of extra articular distal end radius fractures treated with using these two modalities of treatment, closed reduction plaster cast immobilisation with cross $\mathrm{K}$ wire fixation for 25 cases and comparing their functional and anatomical outcome with 25 cases treated with closed reduction plaster cast immobilisation with $\mathrm{k}$ wire fixation by Kapandji's method of fixation in our hospital in 18 months of the study with a average follow-up of 1 year. Regular follow-up has been kept to assess for adequate alignment and the need for operative intervention. AO classification system has been used to classify the fractures. In whichAA3.1, were the commonest type of fracture fallowed by respectively A A2.2, A A3.2, A A2.1 and A A3.3. In a study by Earnshaw et al. $25 \%$ of the patients had a readjustment of the fracture while the limb was in plaster cast and required operative stabilization. The initial reduction was maintained for more than five weeks in only $29 \%$ of the patients and suggested Kirschner wire osteosynthesis is mainly indicated for Colles's fractures located close to the joint (AO types A2 and A3). ${ }^{12}$ Fritz et al. ${ }^{13}$ reported application of Kirschner wire in elderly patients. Clancey ${ }^{14}$ reported good results after Kirschner wire osteosynthesis. A good initial correction of deformity can be achieved using the Kapandji technique. There is some loss of correction at the time of removal of $\mathrm{K}$ wires and then after. Brady et al. ${ }^{15}$ reported on a series of 20 patients at one year follow up and concluded that satisfactory clinical result can be achieved inspite of statistically significant loss of dorsal angulation on radiographs. The dorsal comminution and the subsequent 
loss of dorsal buttress was postulated to be the cause of recurrence of dorsal angular deformity. ${ }^{15}$ McQueen and Caspers, reported significant disability in a group of patients in which fracture healing with 12 degrees dorsal angulation was combined with $2 \mathrm{~mm}$ radial shortening. We noted in our series that though there was a tendency for a decrease in the correction with follow-up, it was not statistically significant. ${ }^{16}$ In our study Anatomical end results were satisfactory in 24 and unsatisfactory in 1 of the subjects treated with closed reduction below elbow cast immobilisation and cross $\mathrm{k}$ wire fixation. Anatomical end results were satisfactory in 18 and unsatisfactory in 7 of the subjects treated with closed reduction below elbow cast immobilisation and $\mathrm{K}$ wire fixation by Kapandji's method. Functional end results were excellent in 7 cases, good in 17 cases, fair in 1 case and poor in 0 cases treated with closed reduction below elbow cast immobilisation and cross $\mathrm{K}$ wire fixation. Functional end results were excellent in 3 cases, good in 15 cases, fair in 6 cases and poor in 1 case treated with closed reduction below elbow cast immobilisation and cross $\mathrm{K}$ wire fixation by Kapandji's method. Azzopardi et al. did a study for unstable, extra-articular fractures of the distal radius to compare the outcome of immobilizing in a cast alone with that using supplementary percutaneous pinning. They concluded that patients treated by percutaneous wires had a statistically significant improvement in dorsal angulations (mean 7), radial length (mean $3 \mathrm{~mm}$ ) and radial inclination (mean $3 \mathrm{~mm}$ ) at one year. ${ }^{17}$

\section{CONCLUSION}

On completion of this study some conclusions have been formed:

1. Kapandji's method and our proposed method of cross $\mathrm{K}$ wire fixation were used to treat extra articular fractures of distal end radius in which cross K-wire method proved to be better than Kapandji's method of intrafocal $\mathrm{K}$ wire fixation both functionally and anatomically.

2. In cases with higher communition (AA3.1 to AA3.3) cross $\mathrm{K}$ wire method had far better results than Kapandji's method but results were similar in cases with less communition.

3. The probable cause behind these differences could be in Kapandji's method, presence of implant at fracture site hampering the healing and creation of a step at fracture site of the diameter of $\mathrm{K}$ wire.

4. Higher degree of communition was seen in older age group probably due to osteoporosis in whom cross $\mathrm{k}$ wire method proves to be better modality of treatment.

5. In cases with dorsal communition treated with Kapandji's fixation dorsal tilt recurrence was noted post reduction as dorsoventral $\mathrm{K}$-wire had poor hold in near cortex.

6. Despite of these results we suggest method of choice in these fractures treatment should be made according to judgment of individual surgeon.

Funding: No funding sources

Conflict of interest: None declared

Ethical approval: The study was approved by the institutional ethics committee

\section{REFERENCES}

1. Abbarzadegon $\mathrm{H}$, Jonsson $\mathrm{U}$, von Sivers $\mathrm{K}$. Prediction of instability of Colle's fracture. Acta Orthop Scand. 1989 Dec;60(6):646-50.

2. Sarmiento A, Pratt GW, Berry NC, Sinclair WF. Colle's fracture. J Bone Joint Surg. 1975 Apr;57(3):311-7.

3. Barton JR. Views and treatment of an important injury to the wrist. Medexaminer. 1838;1:365.

4. Brand PW, Beach RB, Thompson DE. Relative tension and potential excursion of muscles in the forearm and hand. J Hand Surg. 1981;6:209-19.

5. Bacorn RW, Kurtzke JF. Colle's fracture: study of 2000 cases from the New York state workmen's compensation board. J Bone Joint Surg. 1953 July;35(3):643-58.

6. Lindstrom Anders. Fractures of the distal radius: a clinical and statistical study of end results. Acta Orthop Scand. 1959;41:1-118.

7. Mcbride ED. Gartland and Werley criteria. In: Mcbride ED, eds. Disability Evaluation 4th ed. Philadelphia: J.B. Lippincott; 1948.

8. Small GB. Long term follow up of Colle's fracture. J Bone Joint Surg. 1965;47B:80-5.

9. Mah E, Atkinson R. Percutaneous Kirschner wire stabilisation following closed reduction of Colle's fracture. J Hand Surg. 1992;17B:55.

10. Older TM, Stabler EV, Cassebaum WH. Colle's fractures: evaluation and selection of therapy. J Trauma. 1965;5:469-76.

11. Abhishek K. Das, Nandkumar Sundaram, Thiruvengita G. Prasad, Suresh K. Thanhavelu. Percutaneous pinning for non-comminuted extraarticular fractures of distal radius. Indian J Orthop. 2011;45(5):422-6.

12. Earnshaw SA, Aladin A, Surendran S, Moran CG. Closed reduction of Colles's fracture: comparison of manual manipulation and finger trap traction: a prospective, randomized study. Bone Joint Surg Am. 2002;84:354-8.

13. Firtz T, Werschning D, Klavora R, Krieglstein C, Friedl W. Combined Kirschner wire fixating in the treatment of Colles' fracture. A prospective, controlled trial. Arch Orthop Trauma Surg. 1999;119:171-8. 
14. Clancey GJ. Percutaneous Kirschner-wire fixation of Colle's fracture. A prospective study of thirty cases. J Bone Joint Surg Am. 1984;66:1008-14.

15. Brady O, Rice J, Nicholson P, Kelly E, O'Rourke SK. The unstable distal radial fracture one year post Kapandji intrafocal pinning. Injury. 1999;30:251-5.

16. McQueen M, Caspers J. Colles' fracture: does the anatomical result affect the final function? J Bone Joint Surg [Br]. 1988;70-B:649-51.

17. Azzopardi T, Ehrendorfer S, Coulton T, Abela M. Unstable extra-articular fractures of the distal radius, a prospective, randomised study of immobilisation in a cast versus supplementary percutaneous pinning. J Bone Joint Surg Br. 2005;87-B:837-40.

DOI: 10.5455/2320-6012.ijrms20150412

Cite this article as: Patil P, Gaonkar K, Patil A,

Gaonkar N, Gupta K, Patel N, Kulkarni H. Prospective study of treatment of extraarticular fractures of distal end radius by cross $\mathrm{K}$ wire fixation and cast immobilisation and its comparison with Kapandji's method of intrafocal pinning anatomically and functionally. Int J Res Med Sci 2015;3:883-90. 